\title{
Helicobacter pylori Infection Is Associated with Development of Irritable Bowel Syndrome
}

\author{
Antonio Barrios*, Adriana Barrios Fernandez, Angela Alvarez and Eviralda Méndez
}

Las Torres Clinic, Quetzaltenango, Guatemala

\begin{abstract}
Background/Objectives: The role of Helicobacter pylori in the pathogenesis of irritable bowel syndrome (IBS) was investigated in 38 subjects, including 16 males (42\%) and 22 females $(58 \%)$, all of who had been diagnosed with IBS but showed no improvement in response to treatment. Methods: Colonoscopy, biopsy and rapid urease test (CLO-test). Results: Nineteen patients were $H$. pylori-positive (50\%) and 19 were H. pylori-negative (50\%). One patient in this study previously presented colonic carcinoma. Conclusions: All H. pylori-positive patients received treatment and showed improvement, including the patient with colonic carcinoma. Initially, the carcinoma presented $99 \%$ of stenosis, but after one month of treatment the stenosis had decreased to $50 \%$. As a result of this investigation, we consider that the presence of $H$. pylori in the colonic mucosa is another important co-factor in the pathogenesis of IBS that should also be considered in the development of colonic carcinoma.
\end{abstract}

\section{Introduction}

Irritable bowel syndrome (IBS) comprises a group of functional bowel disorders, in which abdominal discomfort or pain is associated with defecation or a change in bowel habits. This syndrome has features of disordered defecation. ${ }^{1}$

For centuries, physicians and historians have recognized that it is common for maladies to afflict the intestinal tract and produce symptoms of pain, nausea, vomiting, diarrhea, constipation, difficult passage of food or feces, or any combination of the above. When persons experience these symptoms with sufficient severity, such that they impact daily life, the symptoms can be defined as an illness that necessitates medical care. In modern times, the physician caring for these patients seeks to identify metabolic, infectious, neoplastic, and other structural abnormalities. If such abnormalities are not found, the patient is - often by exclusionconsidered to have a functional gastrointestinal disorder. ${ }^{1}$

However, we now have better knowledge of the micro-inflammatory phenomena associated with IBS. This syndrome has been

Keywords: $H$. pylori; Irritable bowel syndrome; CLO-test

Abbreviations: H. pylori, helicobacter pylori; IBS, irritable bowel syndrome; FBD, functional bowel disorders; SIBO, small intestinal bacterial overgrowth

Received: 27 June 2016; Revised: 08 October 2016; Accepted: 20 October 2016

DOI: 10.14218/JERP.2016.00014

*Correspondence to: Antonio Barrios, Las Torres Clinic, 19 Avenida 2-67 Zona 3, Quetzaltenango, 09001. Guatemala. Tel: (502) 7763-1184, Fax: (502) 7761-2262, E-mail: antoniobarriosmd@gmail.com characterized as having an increased number of intraepithelial cells and mast cells in the colon. ${ }^{2,3}$ It is speculated that this microinflammation may be the source of the hypersensitivity of nerve endings in the intestinal mucosa, which then helps to induce or perpetuate the symptoms. ${ }^{4}$ In the latest version of the Rome IV criteria, IBS experts recommended that future research focusing on this type of patient investigate luminal content (e.g., microbiota, metabolomic factors) and compare these data with findings in the mucosa. ${ }^{5}$

With the implementation of breath testing for diagnosis of digestive diseases, an important segment of patients (approximately $60 \%$ ) have been found to have IBS. Among these patients, some have small intestinal bacterial overgrowth syndrome (SIBO) and tested positive in the breath test for Helicobacter pylori $\mathrm{C}_{13}{ }^{6} \mathrm{Fol}-$ lowing treatment for each of these separate pathologies, the patients were found to have resolved their original illness and symptoms. Therefore, we designed an investigation to demonstrate the presence of $H$. pylori in the colonic mucosa of patients with IBS.

\section{Methods}

We studied 38 patients $(n=38)$ ranging in age from 9-87 years old. There were 16 males (42\%) and 22 females (58\%). All of the patients had been diagnosed and treated for IBS without showing any improvement in their symptoms. We excluded patients who were diabetic, immunosuppressed or who had recently undergone digestive surgery.

\section{Colonoscopy}

Twenty-four hours prior to the procedure, we prescribed a liquid diet and the laxative solution Fleet (sodium phosphate monobasic $2.4 \mathrm{~g}$ and sodium phosphate dibasic $0.9 \mathrm{~g}$ ). Each patient was given two $45-\mathrm{mL}$ bottles of the laxative solution and told to drink one in the morning and the second one in the afternoon. This preparation is used to cleanse the entire colon of fecal material, which allows for a clear view during examination. After the cleansing, the patient fasted from midnight or for at least 12 hours. We then performed a standard colonoscopy, using propofol as a sedative, and took a biopsy of the colonic mucosa.

\section{Biopsy}

The biopsy was processed using the rapid urease test (CLO-test; Kimberly-Clark). The results of this test were interpreted by the color change reading between 2 and 12 hours. As medical prac- 


\section{HELICOBACTER PYLORI IN IBS.}

\begin{tabular}{|c|c|}
\hline AGE & PATIENTS \\
\hline $0-10$ & 1 \\
\hline $11-20$ & 0 \\
\hline $21-30$ & 4 \\
\hline $31-40$ & 8 \\
\hline $41-50$ & 6 \\
\hline $51-60$ & 7 \\
\hline $61-70$ & 7 \\
\hline $71-80$ & 4 \\
\hline $81-90$ & 1 \\
\hline
\end{tabular}

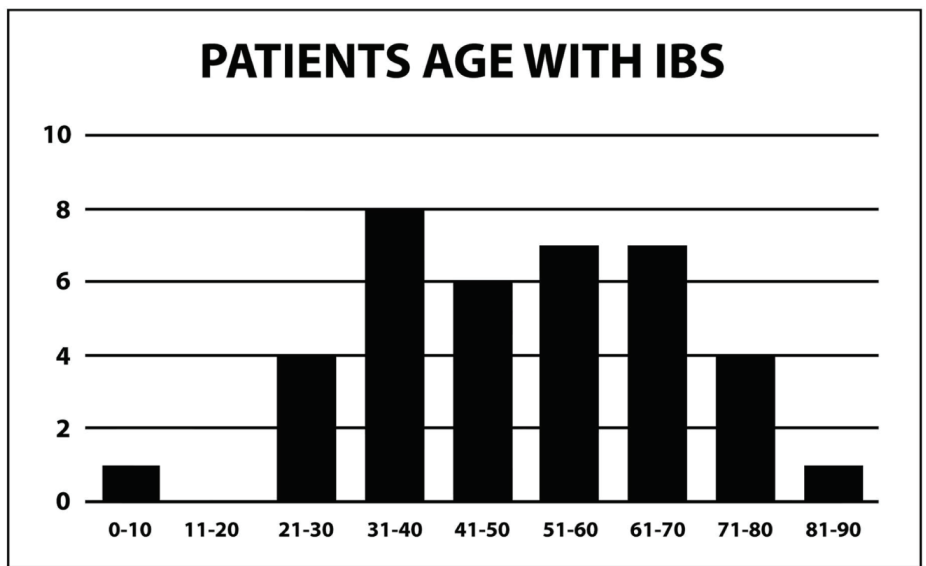

TOTAL: 38 PATIENTS

MALE: $16(42 \%) \quad$ H. PYLORI POSITIVE $19(50 \%)$ AGES FROM 9 - 81 YEARS OLD

Fig. 1. Among the 38 patients studied $19(50 \%)$ were $H$. pylori-positive and $19(50 \%)$ were $H$. pylori-negative. One patient presented with colonic carcinoma, which was located $20 \mathrm{~cm}$ from the external anal sphincter; this patient was also $\mathrm{H}$. pylori-positive.

titioners, we favor the CLO-test for its convenience, affordability and, above all, its accuracy; it has a sensitivity of $98 \%$ and a specificity of $97 \% .^{7}$ Results are available after 20 minutes, and the bacteriostatic agent is in gel form, which ensures a lower incidence of false positives. ${ }^{8,9}$ Being that IBS is one of the functional bowel disorders (FBD) in which there is absence of obvious anatomic or physiologic abnormalities identified by routine diagnostic examination, we took only one biopsy per CLO-test disc, usually in distal colon, avoiding contamination with feces.

\section{Results}

Among the 38 patients studied 19 (50\%) were $H$. pylori-positive and $19(50 \%)$ were $H$. pylori-negative. One patient presented with colonic carcinoma, which was located $20 \mathrm{~cm}$ from the external anal sphincter; this patient was also H. pylori-positive (Fig. 1). All of the patients completed their treatment. All H. pylori-positive patients received a 10-14 day cycle of triple or quadruple therapies, composed of one proton pump inhibitor (lansoprazole, omeprazole, esomeprazole, or pantoprazole) plus two of the following antibiotics: amoxicillin, clarithromycin, metronidazole, tetracycline or tinidazole and bismuth subsalicylate. Allergies or tolerance to any of the antibiotics was taken into consideration in order to avoid treatment failure. Symptoms such as abdominal pain, intestinal dysmotility (diarrhea, constipation or both) and discomfort (abdominal bloating, abdominal distension or flatulence) were no longer present after the $H$. pylori infection treatment (described above) had concluded.

\section{Discussion}

The objective of this pilot study was to determine the role that $H$. pylori plays in the pathogenesis of IBS. We considered that, in general, patients prefer non-invasive diagnostic methods. How- ever, non-invasive methods are often less sensitive and less specific. Invasive methods, such as endoscopy, are unpleasant but are highly sensitive and specific and have the added advantage of sampling at the exact target location. The Kimberly-Clark CLOtest (a commercially available optimized form of the rapid urease test) is recognized by medical professionals as the "gold standard" among urease tests because of its accuracy, convenience and affordability. ${ }^{10}$

A culture is useful with antibiotic sensitivities. The accuracy of histology depends on the experience of the examiner and the appropriate staining method. The use of serology, however, does not define the current activity of $H$. pylori and it is less accurate than histology or the rapid urease test. The CLO-test was developed by Barry Marshall, M.D., who, along with Robin Warren, M.D., was the first to discover the correlation between $H$. pylori and gastric ulcers and now gastric cancer. ${ }^{8-10}$ IBS affects up to $20 \%$ of adults worldwide. ${ }^{1}$ It is more common in women, and females are also more likely than men to report their symptoms to doctors. ${ }^{11-13}$ The wording "syndrome" immediately suggests multi-symptomatology.

What is now called IBS has most likely existed for a long time under a number of different names, accompanied by a multitude of explanations and therapies. European names for IBS include "Reizdarm," "Colica mucosa," "Colitis spastica," "Colon irritabile," "Prikkelbare darm syndrome" and many others. ${ }^{14}$ Its physiopathology includes factors such as visceral sensitivity, intestinal motility, psycho-social factors and inflammation. ${ }^{15}$ A group of experts met to study this syndrome in 1988 and agreed on a set of criteria (Rome I criteria); these criteria were revised in 1999 (Rome II) and again in 2006 (Rome III). The following are the most upto-date criteria: recurrent abdominal pain or discomfort for at least 3 days/month within the last 3 months and associated with two or more of the following: 1. improvement with defecation; 2 . onset associated with a change in frequency of stool; 3. onset associated with a change in form (appearance) of stool. ${ }^{3}$ Right now, the Rome IV changed the criteria to: recurrent abdominal pain, on average, at least 1 day per week in the last 3 months, associated 
with 2 or more of the following criteria: 1 . related to defecation; 2. associated with a change in frequency of stool; 3. associated with a change in form (appearance) of stool. "Criteria fulfilled for the last 3 months with symptom onset at least 6 months before diagnosis."16 However, there is also data suggesting that this syndrome can be associated with infectious factors. For example, in early studies, $76 \%$ of IBS subjects produced an abnormal breath test result, suggesting the possibility of SIBO. ${ }^{5}$ Spiller et al. also found a six-fold increase in the number of enterochromaffin cells and intraepithelial lymphocytes in patients with postinfectious IBS, relative to healthy controls. ${ }^{17}$ These changes are qualitatively and quantitatively similar to the immune-histological findings in biopsies of colon mucosa obtained 2 weeks after an infection by Campylobacter. ${ }^{3,16}$

Barbara et al. provided a key fact: there is a positive correlation between the intensity of mastocytic alterations (activated mast cells found next to the nerve endings in the colon mucosa, which does not occur in healthy controls) and the frequency and intensity of abdominal pain in IBS patients. ${ }^{2,18}$ Considering that similar inflammatory changes have been noted in both IBS and infections produced by Campylobacter, and that a significant percentage of patients with IBS $(76 \%)$ are positive for SIBO, this research indicates that it is important to consider H. pylori as a co-factor in IBS and probably colon cancer. ${ }^{19}$

Gerard et al. studied 31 patients with normal colonoscopy results and investigated the clinical signs of IBS via rectal barostat (pressure-controlled balloon distension in the rectum). Induction of typical abdominal discomfort (far from the balloon) defined the examination as positive.

It is interesting to observe how patients with visceral hypersensitivity also exhibit $H$. pylori infections. This fact suggests that this bacterium may be involved in triggering abdominal pain. ${ }^{20}$

Finally, the US Food and Drug Administration approved rifaximin, a nonabsorbable antibiotic, for the treatment of IBS with predominant diarrhea. In two large clinical trials, 2 weeks of treatment with rifaximin $(550 \mathrm{mg}$, three times daily) in patients with nonconstipated IBS resulted in significantly more patients reporting adequate relief of global IBS symptoms and bloating during the first 4 weeks of follow-up. ${ }^{14}$

After completing the pilot study presented herein, we are now planning the primary study that will incorporate biopsy culture into the investigation methods in order to investigate the role of $H$. pylori in the development of IBS.

\section{Conclusions}

All H. pylori-positive patients received treatment and showed improvement, including the patient with colonic carcinoma. Initially, the carcinoma presented $99 \%$ of stenosis, but after one month of treatment, the stenosis had decreased to $50 \%$. As a result of this investigation, we consider that the presence of $H$. pylori in the colonic mucosa is another important co-factor in the pathogenesis of IBS that should also be considered in the development of colonic carcinoma.

\section{Acknowledgements}

We are grateful to American Manuscript Editors who helped to revise the English translation of the manuscript.

\section{Conflict of interest}

The authors have no conflict of interests related to this publication.

\section{Author contributions}

Conception and design of study (ABE), acquisition of data (ABE, $\mathrm{AA}, \mathrm{EM})$, analysis and/or interpretation of data (ABE, ABF), drafting the manuscript (ABE), revising the manuscript critically for important intellectual content (ABE, $\mathrm{ABF}$ ), approval of the version of the manuscript to be published (ABE, ABF, AA, EM).

\section{References}

[1] Drosman DA, ed. The Functional Gastrointestinal Disorders, Diagnosis, Pathophysiology and Treatment: A Multinational Consensus. Roma II, Multinational Working Teams. 2nd ed. McLean: Degnon Associates, 2000:355.

[2] Barbara G, Stanghelllini V, De Giogio R, Cremon C, Cottrell GS, Santini D, et al. Activated mast cells in proximity to colonic nerves correlation with abdominal pain in irritable bowel syndrome. Gastroenterology 2004;126(3):693-702. doi:10.1053/j.gastro.2003.11.055.

[3] Mearin F, Perello A. Balboa A. Irritable bowel syndrome and inflammatory bowel disease: Is there a connection? Gastroenterol Hepatol 2009;32(5):364 372. doi:10.1016/j.gastrohep.2008.12.007.

[4] Mearin F. Síndrome del intestino irritable: nuevos criterios de Roma III. Med Clin 2007;128(9):335-343. doi:10.1157/13099805.

[5] Boeeckxstaens G, Camilleri M, Sifrim D, Houghton L, Elsenbruch S, Lindberg G, et al. Fundamentals of Neurogastroenterology: Physiology/MotilitySensation. Gastroenterology 2016;150(6):1292-1304.e2. doi:10.1053/j.gastro.2016.02.030.

[6] Pimentel M. AGA Perspectives Amo. Available from: www.gastro.org, pp. 4 Cited 2015.

[7] Kimberly-Clark, CLO-test, Rapid Urease Test. Trusted Clinical Solutions. 1-2. www.kchealthcare.com.

[8] Dye KD, Marshall MJ, Frierson HF, Barret LJ, Guerrant RL, McCallum RW. Is CLOtest alone adequate to diagnose Campylobacter pyloridis. Am J Gastroenterol 1988;83:1032.

[9] Marshall BJ, Warren JR, Francis GJ, Langton SR, Goodwin CS, Blincow E. Rapid Urease Test in the management of Campylobacter pyloridis associated gastritis. Am J Gastroenterol 1987;82(3):200-210.

[10] Ouwehad A, Vaughan E. Gastrointestinal Microbiology. New York: Taylor \& Francis, 2006.

[11] Tompson WG. Gut Reaction. New York: Plenum, 1989

[12] Talley NJ, Stanghellini V, Heading RC, Koch KL, Malagelada JR, Tytgat GNJ. Functional Gastrointestinal Disorders. Gut 1999;45(Suppl II):II37-II42. doi: 10.1136/gut.45.2008.ii37.

[13] Corazziari E. Approach to the Patient with Chronic Gastrointestinal Disorders. Roma: Messaggy Universita "La Sapiensa", 1999.

[14] Valenzuela J, Alvarado J, Cohen H, Damiao A, Francisconi C, Frugone L, et al. Un consenso latinoamericano sobre el síndrome del intestino irritable. Gastroenterol Hepatol 2004;27(5):325-343. doi:10.1016/S0210-5705(03)70470-1.

[15] Basseri RJ, Weitsman S, Barlos GM, Pimentel M. Antibiotics for the treatmen of irritable bowel syndrome. Gastroenterol Hepatol (N Y) 2011;7(7):455-493.

[16] Lacy BE, Mearin F, Chang L, Chey WD, Lembo AJ, Simren M, et al. Bowel Disorders. Gastroenterology 2016;150(6):1393-1407.e5. doi:10.1053/j.gastro. 2016.02.031.

[17] Spiller RC, Jenkins D, Thornley JP, Hebden JM, Wright T, Skinner M, et al. Increased Rectal Mucosal Enteroendocrine Cells, T Lymphocytes and Increased Gut Permeability Following Acute Campylobacter Enteritis and in Post-Dysenteric Irritable Bowel Syndrome. Gut 2000;47(6):804-811. doi:10.1136/gut. 47.6.804.

[18] Park CH, Joo Ye, Choi SK, Rew JS, Kim SJ, Lee MC. Activated Mast Cells Infiltrate in Close Proximity to Enteric Nerves in Diarrhea Predominant Irritable Bowel Syndrome. J Korean Med Sci 2003;18(2):204-210. doi:10.3346/ jkms.2003.18.2.204

[19] Lopez-Brea M. H. Pylori. Microbiología Clínica y Tratamiento. In: Mosby/ Doyma Libros D.L., ed. Madrid, 1995:225-227.

[20] Gerards C, Leodolter A, Blasbrenner B, Malfertheiner P. H. pylori infection and Visceral Hypersensitivity in Patients with Irritable Bowel Syndrome. Dig Dis 2001;19(2):170-173. doi:10.1159/000050673. 